\title{
Derivation of Oligodendrocyte Precursors from Adult Bone Marrow Stromal Cells for Remyelination Therapy
}

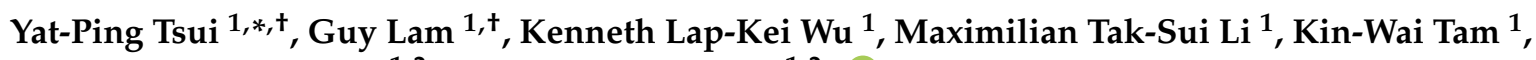 \\ Daisy Kwok-Yan Shum ${ }^{1,2}$ and Ying-Shing Chan $1,2, * \mathbb{D}$ \\ 1 School of Biomedical Sciences, LKS Faculty of Medicine, The University of Hong Kong, Hong Kong, China; \\ u3506833@connect.hku.hk (G.L.); kenneth_wu@hku.hk (K.L.-K.W.); tslimax@hku.hk (M.T.-S.L.); \\ anthonykwtam@connect.hku.hk (K.-W.T.); shumdkhk@hku.hk (D.K.-Y.S.) \\ 2 State Key Laboratory of Brain and Cognitive Sciences, The University of Hong Kong, Hong Kong, China \\ * Correspondence: h0694071@connect.hku.hk (Y.-P.T.); yschan@hku.hk (Y.-S.C.) \\ + These authors contributed equally to this work.
}

check for

updates

Citation: Tsui, Y.-P.; Lam, G.; Wu, K.L.-K.; Li, M.T.-S.; Tam, K.-W.; Shum, D.K.-Y.; Chan, Y.-S. Derivation of Oligodendrocyte Precursors from Adult Bone Marrow Stromal Cells for Remyelination Therapy. Cells 2021, 10, 2166. https://doi.org/10.3390/ cells10082166

Academic Editor:

Dominique Debanne

Received: 1 July 2021

Accepted: 13 August 2021

Published: 22 August 2021

Publisher's Note: MDPI stays neutral with regard to jurisdictional claims in published maps and institutional affiliations.

Copyright: (C) 2021 by the authors. Licensee MDPI, Basel, Switzerland. This article is an open access article distributed under the terms and conditions of the Creative Commons Attribution (CC BY) license (https:/ / creativecommons.org/licenses/by/ $4.0 /)$.

\begin{abstract}
Transplantation of oligodendrocyte precursors (OPs) is potentially therapeutic for myelin disorders but a safe and accessible cell source remains to be identified. Here we report a two-step protocol for derivation of highly enriched populations of OPs from bone marrow stromal cells of young adult rats (aMSCs). Neural progenitors among the aMSCs were expanded in non-adherent sphere-forming cultures and subsequently directed along the OP lineage with the use of glialinducing growth factors. Immunocytochemical and flow cytometric analyses of these cells confirmed OP-like expression of Olig2, PDGFR $\alpha$, NG2, and Sox10. OPs so derived formed compact myelin both in vitro, as in co-culture with purified neurons, and in vivo, following transplantation into the corpus callosum of neonatal shiverer mice. Not only did the density of myelinated axons in the corpus callosum of recipient shiverer mice reach levels comparable to those in age-matched wild-type mice, but the mean lifespan of recipient shiverer mice also far exceeded those of non-recipient shiverer mice. Our results thus promise progress in harnessing the OP-generating potential of aMSCs towards cell therapy for myelin disorders.
\end{abstract}

Keywords: cell therapy; oligodendrocyte precursors; bone marrow stromal cells; directed differentiation; myelin disorders

\section{Introduction}

White matter diseases encompass vast groups of demyelinating, dysmyelinating, and hypomyelinating disorders which often result in severe loss of motor and cognitive functions, and even death [1-3]. Dysfunction or loss of myelinating oligodendrocytes (OLs) is commonly observed in the pathogenesis of such disorders. Transplantation of oligodendrocyte precursors (OPs) for maturation into myelinating OLs in replacement of lost or dysfunctional OLs thus holds great promise for remyelination therapy and related recovery of function [4-7].

Numerous Phase I trials for transplantation of stem cells and neuroprogenitor cells into the human brain demonstrate the feasibility of cell replenishment therapy for neurological disorder [8-10]. However, transplantation of multipotent stem cells, such as embryonic stem cells and induced pluripotent stem cells (iPSCs), incurs a much greater risk of teratoma formation compared to lineage-restricted progenitors. Moreover, transplantation of embryonic stem cells raises ethical concerns [11,12], while the derivation of OPs from iPSCs currently involves multi-step procedures that require more than 100 days [13-15]. We envision that derivation of OPs from neuroprogenitor cells harbored in bone marrow stroma overcomes these hurdles and paves the way for clinical implementation.

Derivation of myelin-forming Schwann cells from adult bone marrow stromal cells (aMSCs) showed that neural progenitors were harbored in aMSCs [16-21]. We hypothe- 
sized that these neural progenitors could be expanded and differentiated into OPs, without genetic manipulation. In this study, we aim to test if aMSC-derived OPs can mature into myelinating OLs in myelin-deficient shiverer mice.

The ability to derive OPs from cryopreserved aMSC stocks within a short time frame highlights bone marrow banks as a resource that can be tapped into. This facilitates donor matching and shortens the time that patients spend waiting for treatment. Neural progenitors can maintain marker expression profiles despite cryopreservation [22,23], but less is known about the potential to differentiate into OPs following reconstitution. As such, we specifically used aMSCs reconstituted from preservation under liquid nitrogen for the production of OPs as described in this study.

Here we report successful generation of Olig2, NG2, PDGFR $\alpha$, and Sox10-expressing OPs from cryopreserved aMSCs with the use of a 2-step protocol in 21 days. These OPs were capable of forming compact myelin in vitro and, more importantly, in vivo following intracerebral delivery into myelin-deficient shiverer mice. Remyelination observed in the corpus callosum of shiverer mice was accompanied by behavioral rescue from autonomic deficits and extended lifespan. These results give promise to the sourcing of adult bone marrow for neural progenitors that can be expanded and differentiated into OPs for remyelination therapy.

\section{Materials and Methods}

\subsection{Animals}

Young adult Sprague Dawley rats (200-250 g, Charles River Laboratories, Wilmington, MA, USA) were used for bone marrow extraction. OPs were harvested from neonatal Sprague Dawley rats for comparison of marker expression with aMSC-derived OPs. Dorsal root ganglia were harvested from embryonic day 15 Sprague Dawley rats. Homozygous shiverer mice (C3Fe.SWV-MBPShi /J, The Jackson Laboratory, Bar Harbor, ME, USA) were used as recipient of aMSC-derived OPs to demonstrate in vivo myelination as a result of OP transplantation into the corpus callosum. C57BI/6J mice (The Jackson Laboratory) were used to illustrate degree of myelination in the wild type. All experimental protocols were approved by the Committee for Use of Live Animals in Teaching and Research, The University of Hong Kong.

\subsection{Bone Marrow Extraction, aMSC Culture and Cryopreservation}

aMSCs were cultured and characterized according to our previous publications [16-21] with modifications. Briefly, young adult rats were euthanized with anesthetic overdose (pentobarbital $150 \mathrm{mg} / \mathrm{kg}$ i.p., Alfasan, Utrecht, The Netherlands). Femurs were then dissected and whole marrow was flushed out with PBS and collected by centrifugation $\left(480 \times g, 5 \mathrm{~min}, 4^{\circ} \mathrm{C}\right)$. Pellets were resuspended in a growth medium comprising MEMalpha medium (Thermo Fisher Scientific, Waltham, MA, USA) supplemented with FBS (10\%, Biosera, Kansas City, MO, USA) and maintained at $5 \% \mathrm{CO}_{2}, 37^{\circ} \mathrm{C}$. Unattached cells were removed by medium change $48 \mathrm{~h}$ later. aMSC colonies were detached with the use of TrypLE Express (Thermo Fisher Scientific) and passaged at 1:3 (v/v) in the growth medium.

aMSC cultures between passages 3-8 were detached with use of TrypLE Express, centrifuged $\left(250 \times g, 5 \mathrm{~min}, 4^{\circ} \mathrm{C}\right)$, resuspended in cryopreservation medium comprising MEM-alpha medium supplemented with 10\% FBS and 10\% DMSO (Sigma-Aldrich, St Louis, MO, USA) and stored in liquid nitrogen in $1.5 \mathrm{~mL}$ cryopreservation vials (Nunc, Roskilde, Denmark). To recover aMSCs, cryopreservation vials were warmed in a $37^{\circ} \mathrm{C}$ water bath until no solid ice was observable in the vials. Contents of cryopreservation vials were diluted in the growth medium, centrifuged $\left(250 \times g, 5 \mathrm{~min}, 24{ }^{\circ} \mathrm{C}\right)$, resuspended in the growth medium, and seeded at a seeding density of 30,000 cells $/ \mathrm{cm}^{2}$.

\section{3. aMSC Proliferation Assay}

Thawed aMSCs seeded in 6-well culture plates were passaged as mentioned above. For each experiment, two 6-well plate wells were seeded with aMSCs. The time between 
each passage was recorded and the number of aMSC per well was recorded between passages 4-8. No statistically significant difference was observed when aMSCs from different rats were used.

\subsection{Neural Progenitor Derivation}

Neuroprogenitor cells were selectively expanded using non-adherent culture [16-21]. Briefly, aMSCs were seeded at 10,000 cells $/ \mathrm{cm}^{2}$ density onto Ultra Low ${ }^{\circledR}$ non-adherent 6-well plates (Corning, Corning, NY, USA) in sphere-forming medium (SFM) comprising DMEM/F12 (Thermo Fisher Scientific) supplemented with 2\% B27 (Thermo Fisher Scientific), bFGF, and EGF (20 ng/mL, Peprotech, Rehovot, Israel). Cultures were maintained for 8-10 days with medium refreshed every $48 \mathrm{~h}$. At timed intervals, selected spheres were partially dissociated via incubation in TrypLE Express for efficient cell counting and determination of proportion of cells immunopositive for the neural stem/progenitor marker nestin [24] and the OL lineage determining factor Olig2 [25,26].

\subsection{Differentiation of Neural Progenitors along the OL Lineage and Cryopreservation}

To obtain OPs, rat bone marrow sphere cells were plated onto 6-well plates coated with poly-D-lysine (Sigma-Aldrich) and laminin (Roche, Basel, Switzerland) in glia inducing medium (GIM) comprising MEM-alpha medium (Thermo Fisher Scientific) supplemented with bFGF (10 ng/mL), PDGF-AA (10 ng/mL), $\beta$-heregulin (100 ng/mL, Millipore), N2 (1\%, Thermo Fisher Scientific), and FBS (2.5\%). OPs were culture-expanded in OP maintenance medium comprising DMEM/F12 medium supplemented with N2, bFGF $(20 \mathrm{ng} / \mathrm{mL})$, and PDGF-AA $(20 \mathrm{ng} / \mathrm{mL})$. OPs were monitored for positivity of 4 key OP markers including Olig2, NG2, PDGFR $\alpha$, and Sox10. OPs were cryopreserved in OP cryopreservation medium comprising 90\% GIM (DMEM/F12 medium supplemented with N2, bFGF, PDGF-AA) with $10 \%$ DMSO in liquid nitrogen.

\section{6. aMSC-Derived OP Proliferation Test}

Thawed aMSC-derived OPs were seeded at 20,000 cells $/ \mathrm{cm}^{2}$ density in 6-well plates. aMSC-derived OPs were passaged upon reaching $80 \%$ confluence. The time between each passage was recorded and the number of OPs per well was recorded for 2 consecutive passages. These OPs could be culture-expanded for at least 2 passages, indicating proper cell yield.

\subsection{Isolation and Primary Culture of Rat OPs}

Primary cultures of rat OPs were prepared as previously described [27]. Briefly, cerebral cortices dissected from neonatal rats (pentobarbital $150 \mathrm{mg} / \mathrm{kg}$ i.p., Alfasan) were diced and digested with $0.25 \%$ Trypsin (Thermo Scientifics) at $4{ }^{\circ} \mathrm{C}$. The digested mixture was triturated with a fire-polished glass pipette and then centrifuged $\left(250 \times g, 4^{\circ} \mathrm{C}\right)$. The cell pellet was resuspended in DMEM/F12 supplemented with FBS (5\%) and the suspension was filtered through a $70 \mu \mathrm{m}$ cell strainer (BD Bioscience, Franklin Lakes, NJ, USA). The filtrate containing OPs was plated onto PDL-coated $75 \mathrm{~cm}^{2}$ culture flasks and maintained for 10 days with medium refreshed every $72 \mathrm{~h}$. After 10 days of culture, the flasks were screwed tightly and shaken on an orbital shaker at 200 r.p.m. for $16 \mathrm{~h}$ to release OPs into the medium. The OP-containing medium was centrifuged $\left(250 \times g, 4^{\circ} \mathrm{C}\right)$, resuspended in OP maintenance medium, and plated onto PDL-coated $6 \mathrm{~cm}$ culture dishes.

\section{8. aMSC-Derived OP-Neuron Co-Culture}

Dorsal root ganglia of embryonic day 15 rats were dissociated with TrypLE Express and collected by centrifugation $\left(250 \times g, 5 \mathrm{~min}, 4^{\circ} \mathrm{C}\right)$ [16-21]. Cells were resuspended in neuron maintenance medium comprising Neurobasal medium (Thermo Fisher Scientific) supplemented with 2\% B27 and NGF (20 ng/mL, Millipore, Burlington, MA, USA) and then seeded at 100,000 cells $/ \mathrm{cm}^{2}$ onto poly-D-lysine/laminin-coated plates. Endogenous Schwann cells and fibroblasts were eliminated following brief treatment with 
fluorodeoxyuridine and uridine (10 $\mu \mathrm{M}$ each, Sigma-Aldrich), whereas dorsal root ganglion neurons and neurite network remained adherent on the coated plates.

aMSC-derived OPs were seeded at $10,000 \mathrm{cells} / \mathrm{cm}^{2}$ onto the axonal network of dorsal root ganglion neurons and the co-culture was maintained in myelination medium comprising Neurobasal medium supplemented with B27, NGF neutralizing antibody (5 $\mu \mathrm{g} / \mathrm{mL}$, Abcam, Cambridge, UK), thyroid hormone (10 ng/mL, Sigma-Aldrich), and DAPT (10 ng/mL, Sigma) for 14 days. Myelin-forming OLs and axons in co-cultures were immunostained for myelin basic protein (MBP) and neurofilament 200 (NF200) respectively. Co-cultures were also prepared for examination of compact myelin under transmission electron microscopy. aMSCs in co-culture with dorsal root ganglion neurons were prepared in parallel as controls.

\subsection{Transplantation of aMSC-Derived OPs}

OPs derived from rat bone marrow (300,000 cells in $1 \mu \mathrm{L}$ of DMEM/F12 medium) were delivered into the right corpus callosum (bregma $-1 \mathrm{~mm}$, medial-lateral $1 \mathrm{~mm}$, dorsal-ventral $1.5 \mathrm{~mm}$ ) of myelin-deficient shiverer mice (anesthetized with $2 \%$ isoflurane in $250 \mathrm{ml} / \mathrm{min} \mathrm{O}_{2}$, RWD, Shenzhen, China) on postnatal day 7 using a Hamilton syringe driven by a computer-controlled syringe pump $(0.5 \mu \mathrm{L} / \mathrm{min})$ to ensure optimal delivery and to prevent backflow. For shiverer mice in the control group, fresh DMEM/F12 medium was delivered instead. A total of 42 shiverer mice were used and 2 were lost during the surgery procedure. Of the remaining 40 mice that survived, 17 were used for histological analysis and 23 for lifespan analysis. Eight wild-type C57BL/6J mice were used as controls. Mice were perfused with 4\% PFA at 6- and 12-weeks later and fixed brains were harvested and processed for histological examination under confocal and electron microscopy for MBP-positive OLs and compact myelin. For lifespan analysis, Kaplan-Meier analysis was used to assess and compare survival of mice that received OP transplant versus vehicle control mice.

\subsection{Immunofluorescence}

Cells in culture were fixed with 4\% PFA for $10 \mathrm{~min}$ and washed in PBS for $3 \times 5 \mathrm{~min}$. Fixed cells were incubated in blocking buffer comprising PBS with $3 \% v / v$ normal goat serum (NGS, Millipore) or 1\% v/v BSA (Sigma-Aldrich) and 0.1\% v/v Triton X100 (SigmaAldrich) for $30 \mathrm{~min}$. Samples were incubated with primary antibodies overnight at $4{ }^{\circ} \mathrm{C}$ (listed in Table S1). After washing in 1xPBS thrice, cells were incubated with the appropriate fluorophore-conjugated Alexa Fluor ${ }^{\circledR}$ secondary antibodies (diluted 1:400 in blocking buffer, Thermo Fisher Scientific) for $60 \mathrm{~min}$, followed by 3 rounds of washing in 1xPBS. Hoechst stain (Sigma-Aldrich) was used to counterstain nuclei. Images were viewed under an Olympus IX71 inverted fluorescence microscope equipped with Olympus DP71 camera for image capture. For cell counting, 10 random fields were captured and a minimum of 300 cells were counted per experiment by investigators blinded to the grouping.

Mouse and rabbit isotype controls (1:200, Thermo Fisher Scientific) were used in control experiments (Figure S1).

\subsection{Sample Preparation and Immunohistochemistry}

At 6- and 12-weeks post-injection, mice were deeply anesthetized (pentobarbital $150 \mathrm{mg} / \mathrm{kg}$ i.p., Alfasan) before transcardial perfusion with ice-cold saline followed by $4 \%$ PFA. Brain tissue was dissected, post-fixed overnight in $4 \%$ PFA at $4{ }^{\circ} \mathrm{C}$, and cryoprotected in $30 \%$ sucrose solution. Coronal cryosections $(50 \mu \mathrm{m})$ containing the corpus callosum were prepared (Thermo Fischer Scientific NX50 cryostat). The sections were permeabilized and blocked with 1\% Triton X-100 and 3\% BSA in phosphate buffered saline for $60 \mathrm{~min}$, and then incubated with primary antibodies overnight at $4{ }^{\circ} \mathrm{C}$ (listed in Table S1) followed with the appropriate fluorophore-conjugated Alexa Fluor ${ }^{\circledR}$ secondary antibodies (diluted 1:400 in blocking buffer, Thermo Fisher Scientific) for $3 \mathrm{~h}$. Cell nuclei 
were counterstained with Hoechst 33258 (Sigma-Aldrich). The stained sections were rinse and mounted for viewing and image capture under confocal microscopy (Zeiss LSM 800).

\subsection{Transmisison Electron Microscopy}

PFA-fixed samples were further fixed with 1\% osmium tetroxide, stained with $1 \%$ uranyl acetate, and were then embedded in Epon. Sagittal sections (75-90 nm thick) of the corpus callosum were picked up on formvar/carbon-coated 75 mesh $\mathrm{Cu}$ grids and stained for $20 \mathrm{~s}$ in 1:1 super-saturated uranyl acetate in acetone followed by $0.2 \%$ lead citrate. Images were viewed under a Philips CM100 transmission electron microscope and selected images were captured for ultrastructural analysis of myelin morphology. Within imaged areas of $100 \mu \mathrm{m}^{2}$ of the corpus callosum, myelinated axons showing clear major dense lines within compact myelin and larger than $1 \mu \mathrm{m}^{2}$ in cross-sectional area were counted and assessed for the myelin g-ratio, being the ratio of the inner radius to the outer radius of the myelin sheath.

\subsection{Flow Cytometry}

Cells were dissociated via incubation in TrypLE Express, fixed in 4\% PFA for 5 min, and then sedimented by centrifugation $(250 \times g, 5 \mathrm{~min})$. The pellets were gently washed with PBS and then resuspended in a blocking buffer comprising PBS with 3\% $v / v$ NGS and $0.1 \% v / v$ Triton $\mathrm{X} 100$ for $30 \mathrm{~min}$. The cells were incubated with selected primary antibodies (listed in Table S2) for $2 \mathrm{~h}$ at $4{ }^{\circ} \mathrm{C}$ followed by the appropriate Alexa Fluor ${ }^{\circledR}$ secondary antibodies (diluted 1:400 in blocking buffer, Life Technologies, Carlsbad, CA, USA) for 30 min. Immunolabelled cells were subjected to flow cytometric analysis with use of BD CantoII Analyzer. A minimum of 10,000 cells were analyzed per experiment.

Mouse and rabbit isotype controls (diluted 1:200 in blocking buffer, Life Technologies) were used in the control experiments.

\subsection{Reverse Transcription Polymerase Chain Reaction (RT-PCR)}

Total RNA was extracted using TRIzol (Thermo Fisher Scientific) according to the manufacturer's protocol. Total RNA $(5 \mu \mathrm{g})$ recovered from OPs in culture was used for firststrand cDNA synthesis using PrimeScript Reverse Transcriptase (Takara, Kusatsu, Japan) with Oligo-(dt) primers. PCR was performed with $200 \mathrm{ng}$ cDNA, Taq DNA polymerase (NEB), and primers listed in Table S3. Colorimetric analysis of the resulting bands was performed with use of a Biorad Gel Doc XR imaging system; results were normalized against that of the housekeeping gene GAPDH.

\subsection{Statistical Analysis}

Statistical analyses were performed using GraphPad Prism Software 8 (GraphPad Software Inc., San Diego, CA, USA) and R Studio. Data are presented as mean \pm S.D. Student's $t$-test and Welch's $t$-test were used for statistical analysis and $p$-values $<0.05$ were considered significant.

\section{Results}

\subsection{Characterization of Primary and Cryopreserved aMSCs}

We extracted and expanded aMSCs as reported previously [16-21]. Primary aMSCs (passages 3-8) were fibroblastic in morphology (Figure 1A) and proliferated steadily throughout passage 4 to 8 . Cultures reached $80 \%$ confluence every $31 \mathrm{~h}$ after each passage (Table S4, $n=3$ replicates). Over $95 \%$ of the aMSCs were immunopositive for the mesenchymal stem/progenitor cell markers CD90 (Figure 1B), CD73 (Figure 1C) and CD105 (Figure 1D). The neural stem/progenitor cell marker, nestin, was found positive in $>15 \%$ of the aMSCs (Figure 1F). Notably, the hematopoietic marker CD45 was found positive in but $<1 \%$ of the aMSCs (Figure 1E). The aMSCs were of high purity and devoid of contaminating cells of hematopoietic lineage. This marker expression profile was maintained in aMSCs even after recovery from cryopreservation (Figure S2). 

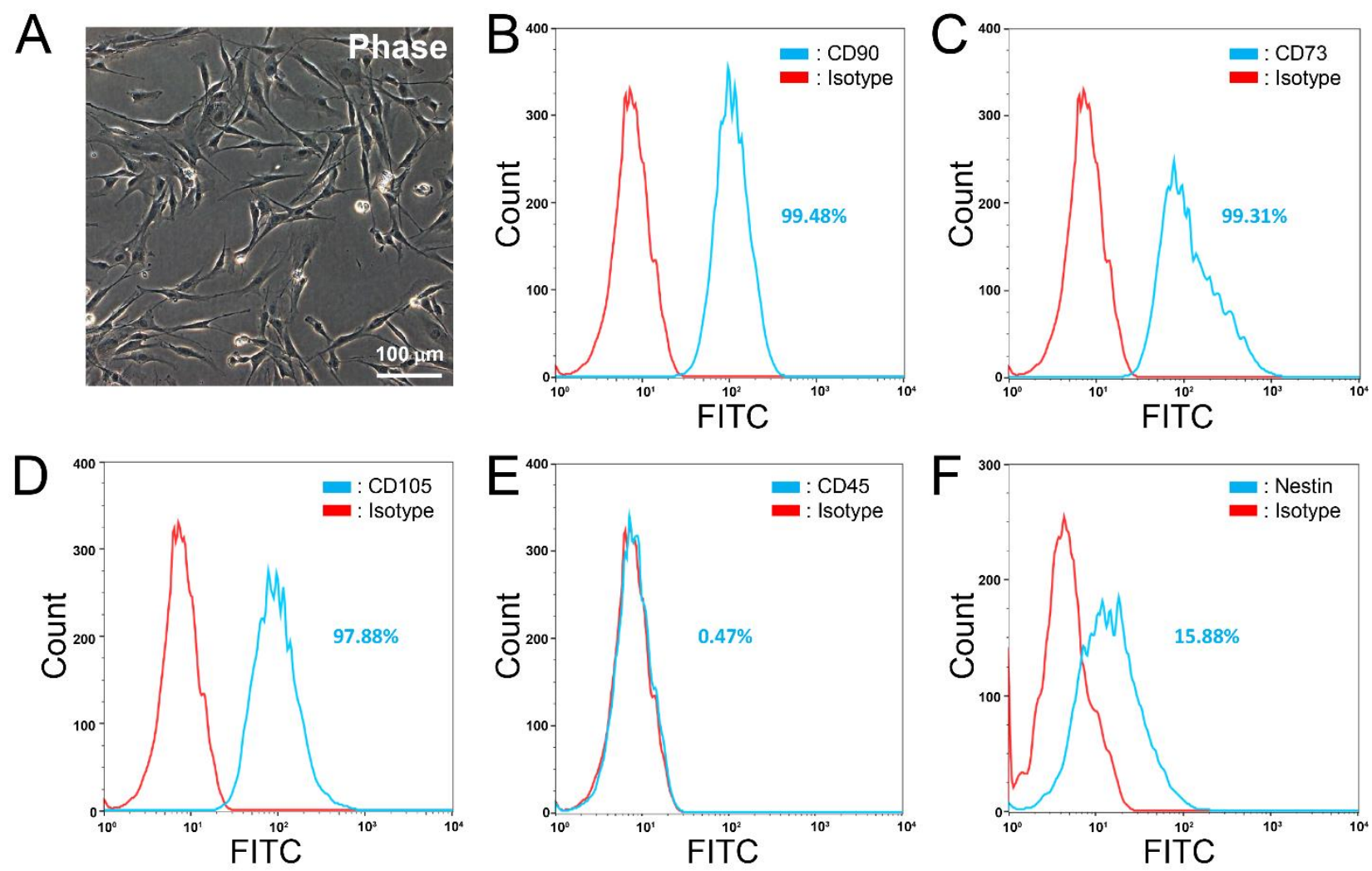

Figure 1. Flow cytometric analysis of aMSCs in culture. (A) Phase contrast micrograph showing fibroblastic morphology typical of aMSCs in passages 3-5. (B-D) Representative histograms showing high expression of mesenchymal stem cell markers CD90 (B, 99.48\%), CD73 (C, 99.31\%) and CD105 (D, 97.88\%). Hematopoietic marker CD45 (E) was only positive in $0.47 \%$ of cells. The neural progenitor marker nestin was positive in $15.88 \%$ of cells $(\mathbf{F}) . n=4$ independent preparations of aMSCs.

\subsection{Derivation of Neural Progenitors through Non-Adherent Culture}

Following transferring to non-adherent culture, aMSCs spontaneously formed spheres that measure $>50 \mu \mathrm{m}$ in diameter within 6 days (Figure 2A). By day 10, 83.15\% $\pm 8.38 \%$ of the sphere cells indicated immunopositivity for the neuroprogenitor cell marker, nestin (Figure $2 \mathrm{~B}, \mathrm{~F}$ ) in contrast to $12.42 \% \pm 2.82 \%$ found among aMSCs maintained in parallel, adherent culture (Figure 2D,F). Incidentally, $89.96 \% \pm 5.45 \%$ of the sphere cells were also immunopositive for glial fibrillary acidic protein (GFAP, Figure 2C,F) in contrast to $0.78 \% \pm 0.45 \%$ among aMSC in parallel, adherent culture (Figure $2 \mathrm{E}, \mathrm{F}$ ). On the contrary, immunopositivity for the OL lineage determining factor, Olig2, was found in $36.49 \% \pm 7.92 \%$ of the sphere cells in non-adherent culture (Figure $2 \mathrm{~B}, \mathrm{~F}$ ), in contrast to only $0.59 \% \pm 0.48 \%$ among aMSCs in adherent culture (Figure 2D,F). Expression patterns of the indicated marker genes among spheres in non-adherent culture were in corroboration with the results of RT-PCR analysis of the transcripts (Figure S3). The results suggest that the sphere-forming cultures fostered selective expansion of neuroprogenitor cells among the aMSCs and that an Olig2-positive subset of the neuroprogenitor cells is poised for fate restriction to the OL lineage. 


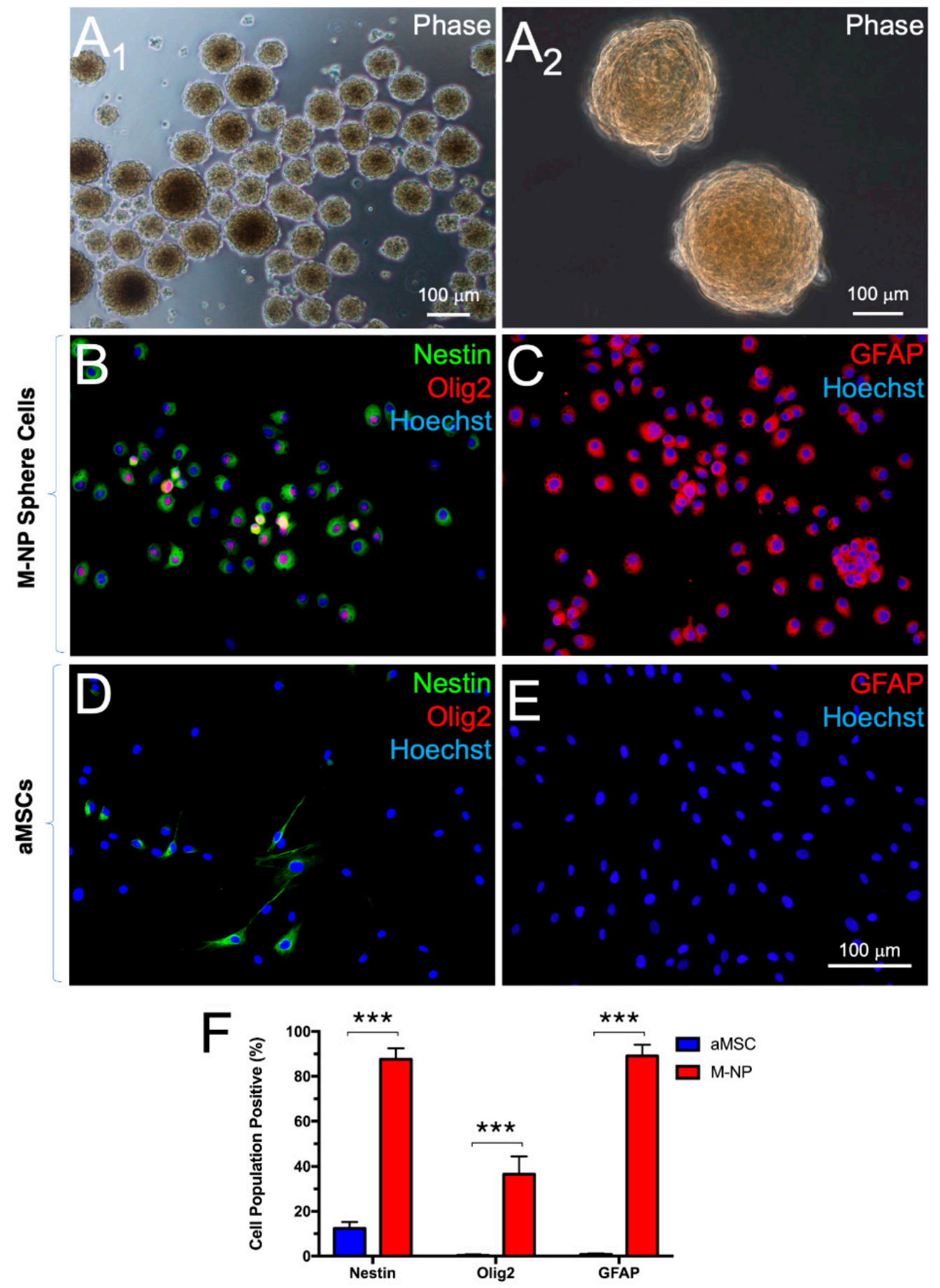

Figure 2. Selective expansion of neural progenitors in non-adherent culture. aMSCs formed spheres by day 6 in non-adherent culture $\left(\mathbf{A}_{\mathbf{1}, \mathbf{2}}\right)$. Increased expression of nestin (B), Olig2 (B), and GFAP (C) were observed in the course of non-adherent culture versus parallel, adherent cultures of aMSCs $(\mathbf{D}, \mathbf{E})$. Histogram showing the percentage of aMSCs positive for the indicated markers (F). $n=5$ independent preparations. ${ }^{* *}: p<0.0001$. Student's $t$-test.

\subsection{Differentiation of aMSC-Derived Neural Progenitors along the OL Lineage}

Following transfer of neurospheres to adherent substratum for glial induction in cultures, cells emigrated from the spheres and formed colonies of process-bearing cells that resembled OPs (Figure 3A). Colonies of OP-like cells were isolated by cold-jet [16-21] and expanded in subcultures. At low density, OP-like cells were bi-/tri-polar in morphology (Figure 3B). As the OP-like cells approached confluence, they became polydendritic 
(Figure 3C). Immunocytochemistry revealed that OP-like cells were positive for the OP markers: Olig2 (Figure 3D), PDGFR $\alpha$ (Figure 3E), NG2 (Figure 3F), and Sox10 (Figure 3F). Flow cytometry further confirmed that $>95 \%$ of the OP-like cells were positive for the four OP markers (Figure 3G-J). The results were corroborated by semiquantitative RT-PCR analysis of transcripts (Figure S4). These OP-like cells were capable of undergoing culture expansion (Table S5, $n=3$ individual preparations) and expressed mature OL markers CNPase and myelin basic protein (MBP) upon withdrawal of the OP mitogens bFGF and PDGF-AA [28] from the maintenance medium (Figure S5). These OP-like cells were therefore capable of maturing into OL-like cells in vitro.
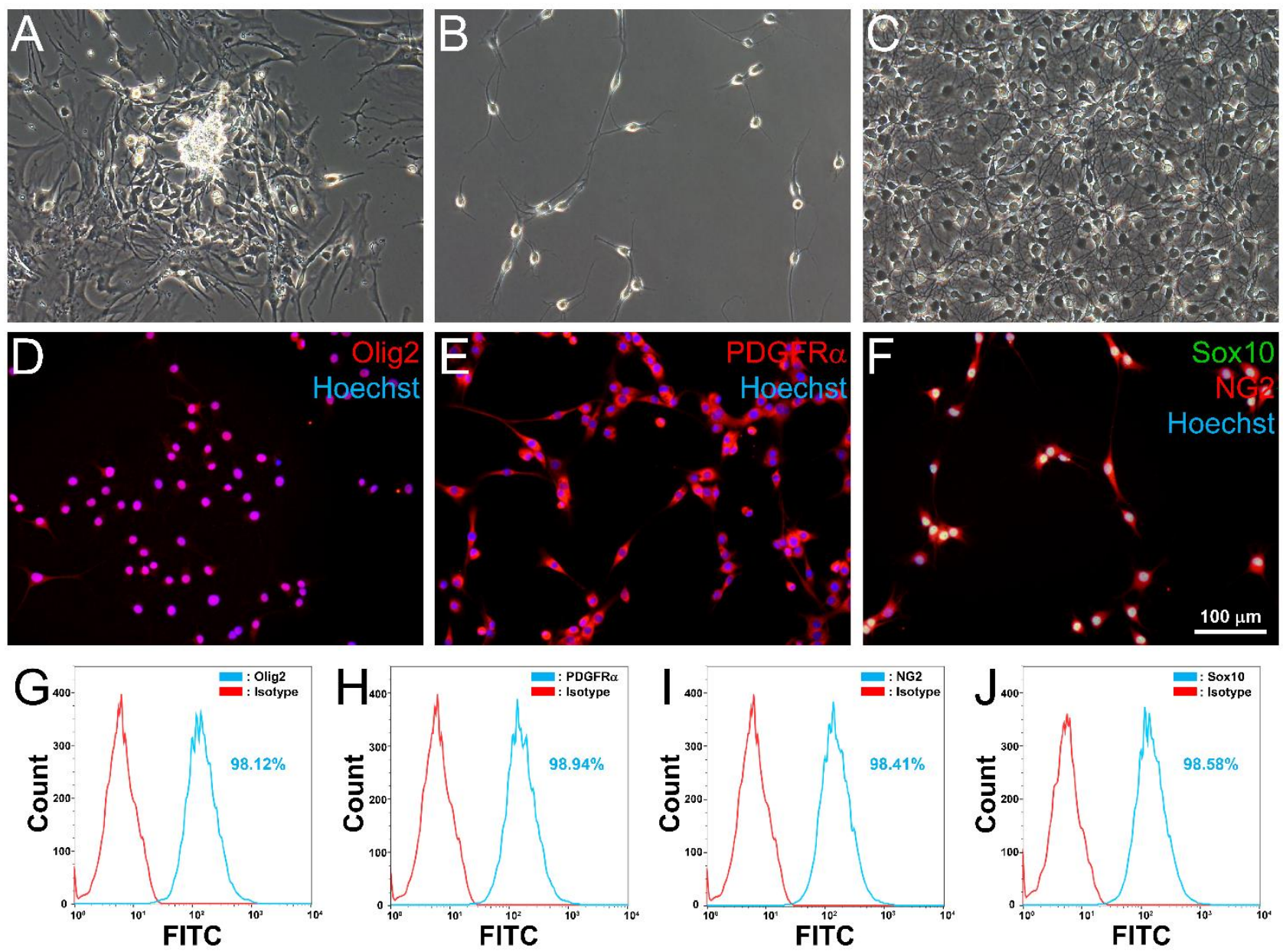

Figure 3. Derivation of OP-like cells. Spindle-shaped cells exited from adherent spheres 7 days after glia induction in adherent culture (A). Following re-plating, cells developed bi/tri-polar OP-like morphology (B). At higher cell density, OP-like cells became polydendritic (C). These cells were positive for the OP markers Olig2 (D), PDGFR $\alpha$ (E), NG2, and Sox10 (F). Flow cytometric analysis of OP-like cells found then immunopositive for Olig2, PDGFR $\alpha$, NG2, and Sox10 in $98.12 \%(G), 98.94 \%(H), 98.41 \%(I)$, and $98.56 \%$ (J) of cells respectively. Histograms of a representative experiment are shown. $n=4$ independent preparations.

\subsection{In Vitro Myelination}

The OP-like cells derived from rat aMSCs were tested for myelinating capacity in co-culture with neurons purified from embryonic day 15 rat dorsal root ganglia. After 2 weeks in co-culture, MBP-positive OLs were found with processes that associated with networks of neurofilament 200 (NF200)-positive axons (Figure 4A-C). Higher magnification images revealed individual OLs bearing MBP-positive processes alongside multiple NF200positive axons (Figure $4 \mathrm{D}-\mathrm{F}$ ). Transmission electron micrographs of the MBP-positive 
domains revealed ultrastructure of compact myelin (Figure $4 \mathrm{G}, \mathrm{g}^{*}$ ), thus confirming that these cells are functional OPs.
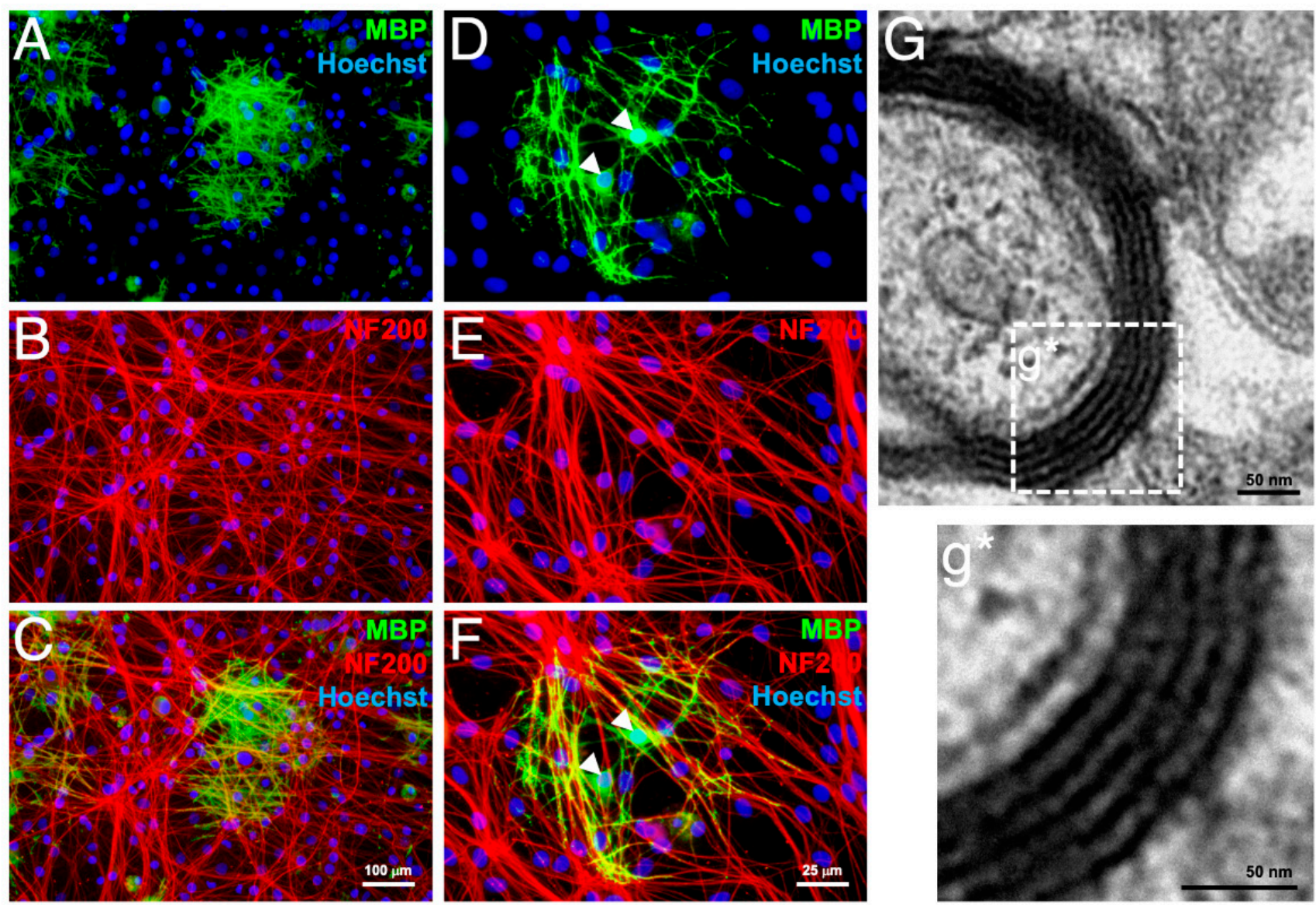

Figure 4. Maturation of OP-like cells into myelinating OLs in co-culture with neurons purified from embryonic day 15 rat dorsal root ganglia. After 2 weeks in co-culture, MBP-positive mature OLs (A) extended processes along NF200-positive axons (B, merged image in $\mathbf{C}$ ). Higher magnification revealed individual OLs bearing multiple MBP-positive processes (D-F). OL cell bodies are indicated by white arrowheads (D,F). Transmission electron micrograph showing ultrastructure of compact myelin in a sample taken from an MBP-positive domain in the co-culture $\left(\mathbf{G}_{,} \mathbf{g}^{*}\right) . n=4$ independent preparations.

Cryopreserved OPs (stored under liquid nitrogen for 2 months) were similarly tested for myelinating capacity in vitro. MBP-positive OLs were observed after 2 weeks in co-culture with dorsal root ganglia neurons (Figure S6), indicating that the myelination capacity of these OPs was preserved despite cryopreservation. By contrast, neither OLs nor myelin was detectable in co-cultures of aMSCs with dorsal root ganglia neurons (Figure S7).

\subsection{In Vivo Myelination and Extended Lifespan Follwing Transplantation of OPs}

To test for the capacity of myelination in vivo, OP-like cells were transplanted into the corpus callosum of myelin-deficient shiverer mice. MBP-positive OLs were observed in the corpus callosum of recipients, both ipsilateral (Figure 5A) and contralateral (Figure 5B) to the injection site by 6 weeks post-transplantation. This indicates that OP-like cells were capable of dispersal from the injection site to other brain regions and maturation into OLs in encounters with host axons in vivo. In line with in vitro results, such OLs produced multiple MBP-positive processes in co-localization with NF200-positive axons (Figure $5 a^{*}, b^{*}$ ). MBP, a necessary component of compact myelin, was not detected in control shiverer mice that received vehicle injections only (Figure 6A). Bundles of myelinated axons were identified in the corpus callosum of shiverer mice by 6 weeks post-transplantation (Figure 6B) but not in control shiverer mice that received vehicle injection (Figure 6A). 

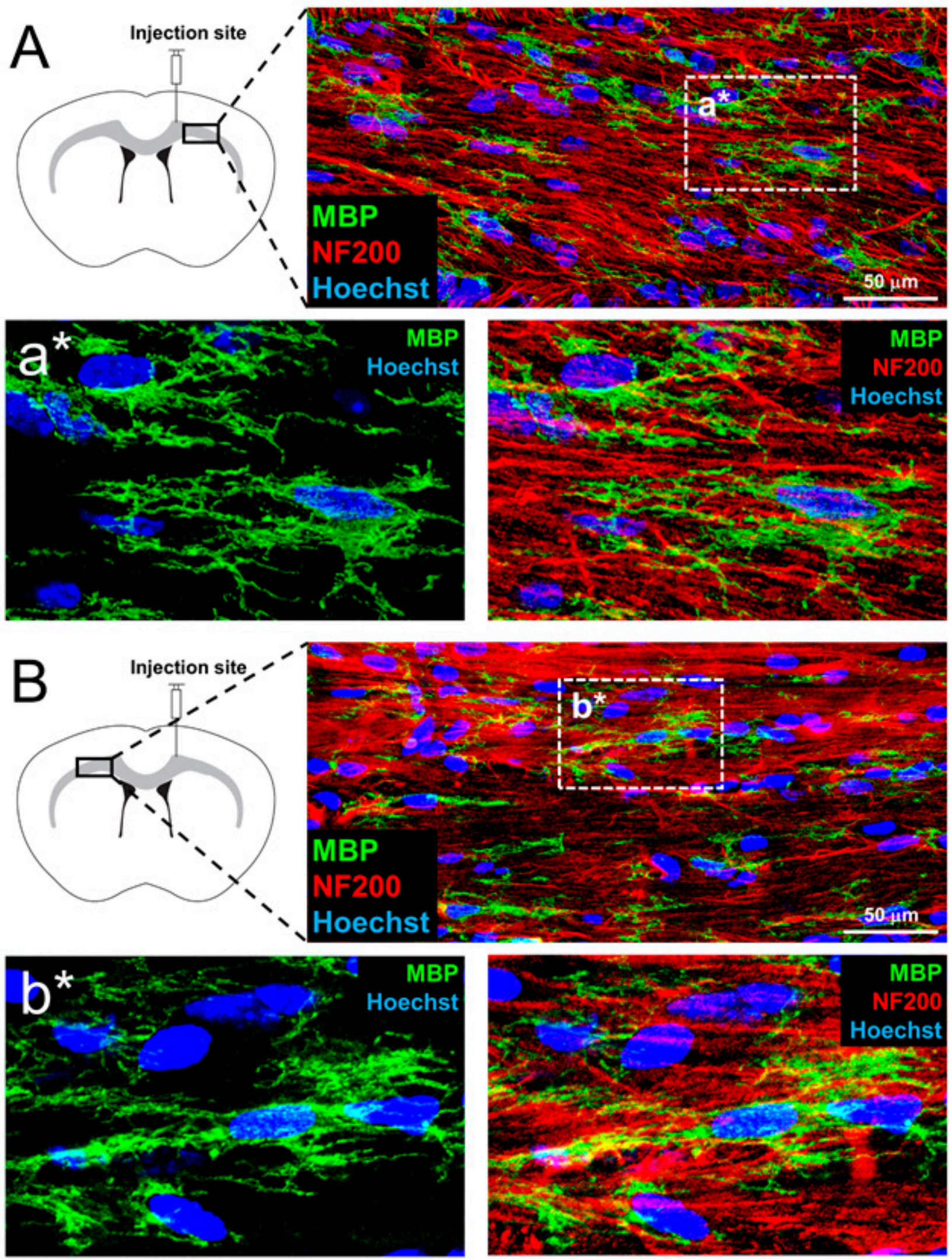

Figure 5. Migration and maturation of aMSC-derived OPs into myelinating OLs in myelin-deficient shiverer mouse model, 6 weeks post-transplantation into the corpus callosum was performed the right hemisphere. MBP-positive OLs were observed in the corpus callosum of, on both the right (A) and the left (B) 6 weeks post-transplantation. Multiple MBP-positive processes along NF200-positive axons $\left(\mathbf{a}^{*}, \mathbf{b}^{*}\right) . n=5$ mice. 


\section{Medium-injected shiverer}
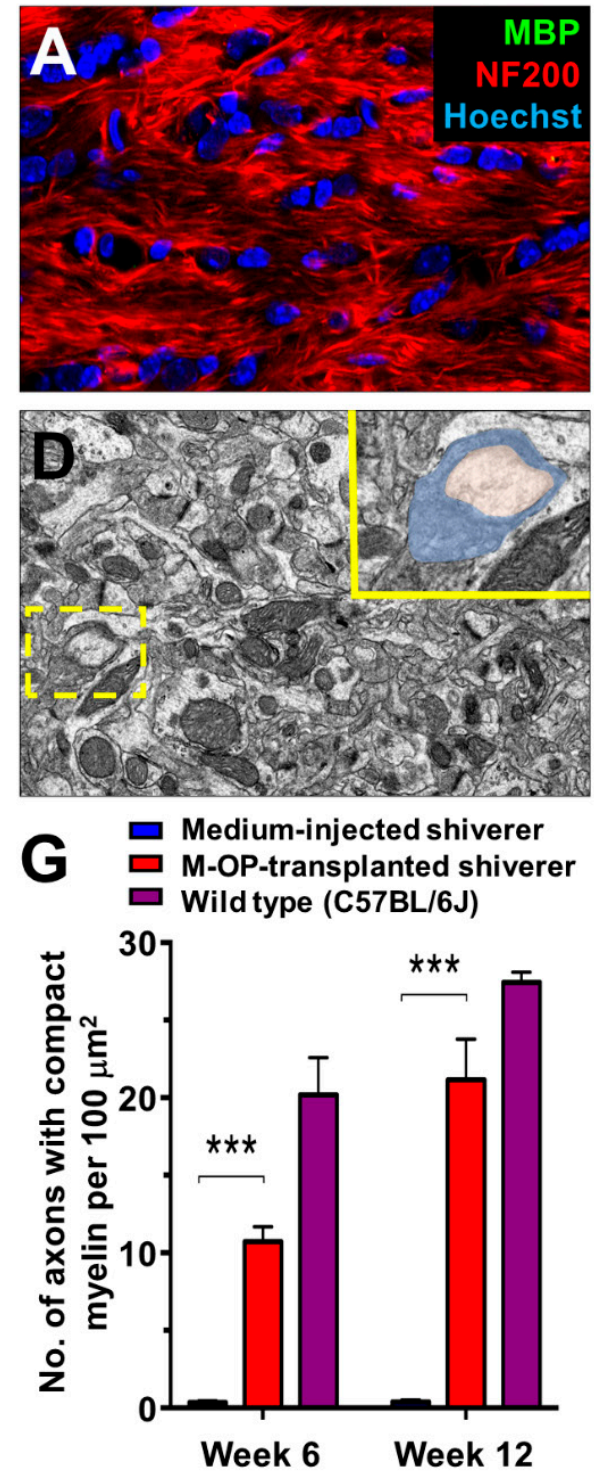

6 weeks post-transplantation
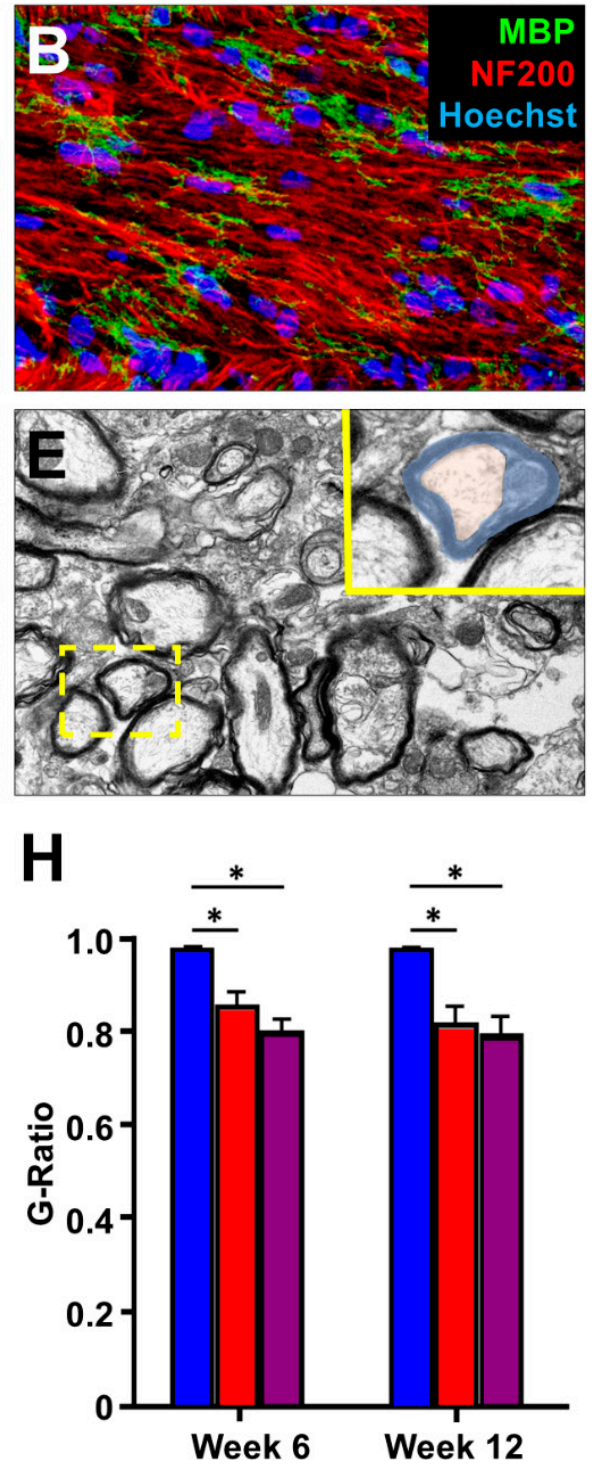

\section{2 weeks post-transplantation}
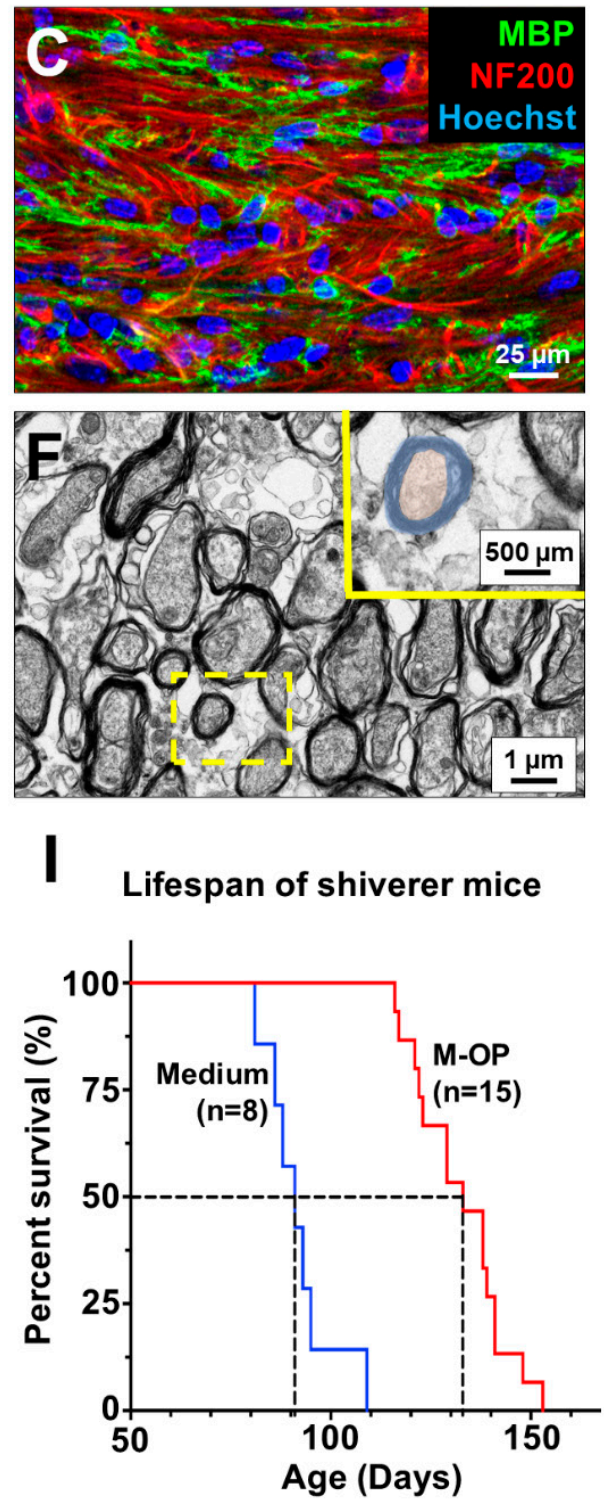

Figure 6. Compact myelin in the corpus callosum and lifespan extension of shiverer mice that received OP transplant into the corpus callosum. Medium-injected controls display no MBP-positivity in the corpus callosum (A). Recipients of OP transplants displayed MBP-positivity in the corpus 6 (B) and 12 weeks (C) post-transplantation. Transmission electron micrographs showing compact myelin with major dense lines in OP recipients 6- (E) and 12-weeks (F) post-transplantation, but not in the medium-injected controls (D) by week 12. Insets highlight OLs (blue) enwrapping axons (orange) (D-F). The density of axons enwrapped by compact myelin was significantly higher (G) with G-ratios comparable to that of wild-type mice (H) in OP recipients compared to controls. OP recipient shiverer mice: $n=5$ (6-week) and $n=4$ (12-week), control shiverer mice: $n=4$ (for both time points). C57BL/6J mice: $n=4$ (for both time points). The average lifespan of the OP recipients was significantly extended by $46.24 \%$ (I), with a median survival time of 133 days compared to 91 days in controls. *: $p<0.05,{ }^{* * *}: p<0.0001$. Student's $t$-test. Shiverer mice: $n=15$ OP recipients, $n=8$ medium controls.

By 12 weeks post-transplantation, myelinated axons were abundant in animals that received OP transplantation (Figure 6C), but not in controls (Figure 6A). Electron micrographs further confirmed the presence of compact myelin ensheathing axons (Figure 6E,F) within the corpus callosum of shiverer mice that received OP transplant. Whereas in controls injected with vehicle, almost all OLs showed partial/no enwrapping of axons (Figure S8). A significantly higher number of axons with compact myelin were observed in recipients of OP-transplant (Figure 6G, $10.72 \pm 0.83$ per $100 \mu \mathrm{m}^{2}$ of corpus callosum) 
compared to recipients of vehicle (Figure $6 \mathrm{D}, \mathrm{G}$ ). The number of myelinated axons per $100 \mu^{2}$ increased to $21.16 \pm 2.26$ by 12 weeks post-transplantation, comparable to wildtype C57BL6J mice (Figure 6F,G). The thickness of myelin observed in recipients of OP transplant was comparable to that in wild-type controls at 12 weeks post-injection as evidenced by G-ratio (Figure $6 \mathrm{H}$ ).

Finally, shiverer mice that received transplant of aMSC-derived OPs demonstrated significant extension of lifespan when compared to the control group (Figure 6I). From the Kaplan-Meier survival curve, the average lifespan of treated animals was significantly extended by $46.24 \%$ (Figure $6 \mathrm{I}$ ), with an increase of the overall median survival time from 91 to 133 days. This suggested that widespread remyelination of the corpus callosum due to OP transplantation was sufficient to bring about the functional rescue of MBP-deficiency in shiverer mice.

\section{Discussion}

The current study demonstrated derivation of OPs capable of maturation into myelinforming OLs from aMSCs. In our two-stage induction protocol, OPs were successfully derived from cryopreserved aMSCs within 20 days. Neural progenitors harbored within aMSC cultures, as shown by nestin (neural stem/progenitor marker) positivity, represent a viable cell source that could be expanded for induction into myelinating glia. The protocol presented here fosters the expansion of neuroprogenitor cells through formation of neurospheres in non-adherent culture. These progenitors are then directed to differentiate into OP-like cells in adherent culture supplemented with glia inducing factors PDGF-AA- [29] and bFGF [30]. Withdrawal of these two factors from the media triggered expression of OL markers in OPs. This mirrored the maturation trajectory of primary cultures of OPs [2,31].

A subset of neural progenitors that were positive for Olig2, the critical OL lineage determining transcription factor, was present in the neurosphere. These Olig2-positive cells likely represented progenitors poised to differentiate along the OL lineage. On the contrary, aMSC-derived Schwann cells (the myelinating glia in the peripheral nervous system) reported in our previous works [16-21] might have been obtained from Olig2-negative neural progenitors. High throughput techniques such as single-cell RNA sequencing will reveal the full differentiation potential within the neurosphere.

OP-like cells were established as functional OPs capable of maturation into myelinating OLs by co-culture with neurons, and by transplantation into shiverer mice. After 2 weeks in co-culture with neurons purified from rat dorsal root ganglia, OPs generated MBP-positive processes that co-localized with multiple axons, and assumed morphology characteristic of OLs [32]. When aMSC-derived OPs were transplanted into the brains of myelin-deficient shiverer mice. MBP-positive OLs were observed 6 weeks posttransplantation. Corroborating with the in vitro assay, MBP-positive processes of OLs were associated with NF200-postive axons. While OPs were delivered only into the right corpus callosum of homozygous shiverer mice, MBP-positive OLs were observed bilaterally in the corpus callosum by 6 weeks post-transplantation, suggesting the characteristic migration capability of OPs after transplantation $[5,10]$. Compact myelin with major dense lines was identified abundantly by electron microscopy when OPs encountered axons both in vitro and in vivo. Persisting survival, integration, and in vivo myelination capacity of the transplanted cells over an extensive timeframe was reflected by the increasing number of myelinated axons from week 6 to week 12 . While we did not directly assess the immune response of these mice, persistent survival of xenografted cells might have been due to perinatal immune tolerance [33,34]. This is concordant to progressive myelination and axonal ensheathment by oligodendroglia over time also reported in pioneering studies $[5,13]$.

Finally, we addressed whether myelin restoration resulted in any functional improvement. Shiverer mice that received OP transplantation had a significantly longer lifespan than non-recipients. This suggested that OPs not only mediated re-establishment of CNS myelin at a structural level but also improved neurological functions and rescued these shiverer mice from premature death due to autonomic deficits. Callosal OL networks 
provide energy to neurons for sustaining axonal function and action potential generation via facilitated glucose delivery [35]. This suggests the possibility of a feedback loop for activity-dependent maturation of OPs into OLs [36] and the formation of compact myelin [37-39]. While the limited number of OPs injected did not rescue motor deficits in shiverer mice, we postulate that future studies that focus on direct remyelination of fibre tracts in the spinal cord and sensorimotor cortices with a sufficient number of OPs would bring about the rescue of motor deficits in these mice.

Taken together, our aMSC-derived OPs were indistinguishable from OPs extracted from cortical tissue, in terms of (i) marker expression, (ii) culture conditions, (iii) in vitro maturation process, and (iv) myelin-formation capacity [27,28,31]. aMSC-derived OPs matured into myelin-forming OLs and re-established compact myelin after being transplanted into the corpus callosum of shiverer mice. Marker expression of these OPs remained stable in culture and we did not observe any tumorigenesis in mice that received OP transplant. Future transplantation studies in immune-deficient mice will ascertain the safety of aMSCderived OPs. Treatment-dependent lifespan extension translated into the partial repair of the innate neurological and autonomic deficits in shiverer mice. This demonstrated efficacy sheds light upon future clinical applications for white matter diseases.

While transplantation of cells directly into the human brain is undoubtedly invasive, the severely debilitating symptoms of myelin disorders justify the risks of undergoing such treatments. Phase I clinical trials for injection of neural and mesenchymal stem cells into the brain of patients suffering from a variety of neurological disorders have been conducted globally with no adverse effects reported in longitudinal studies [8-10]. Furthermore, intrathecal injection also presents itself as a lower-risk option for the introduction of cells into the CNS [40]. With these trials demonstrating the safety of intracranial cell transplantation, clinical use of OP transplant is only limited by the lack of a lineage stable and easy to obtain cell source. Bone marrow aspiration from the posterior iliac crest is an established procedure for obtaining bone marrow [41,42]. Given that aMSC-derived OPs can be culture-expanded, only a limited amount of bone marrow would be sufficient to produce OPs on the scale required for therapeutic use. With lineage stability after cryopreservation and retention of myelin-forming capacity following reconstitution, OPs thus derived have the potential to become "off-the-shelf" products. These advantages serve as a solid foundation for future translations of industrial implications.

\section{Conclusions}

Prior to our study, reported sources of OPs mainly resort to human embryonic stem cells [5,7], iPSCs [13-15], or through direct reprogramming of fibroblast [32]. Despite being effective in remyelination, these approaches confront either ethical issues or safety/technical challenges. Through adopting aMSCs, we avoided ethical issues of using human fetal tissue or embryonic stem cells $[11,12]$. We demonstrated that aMSC cultures harbored neural progenitors that can be directed to differentiate along the OL lineage. Through manipulation of the in vitro niche, including the culture substratum and a combination of growth factors, we were able to derive OPs from cryopreserved aMSCs without genetic/epigenetic manipulation or viral vectors. This circumvents a major technical/safety challenge faced by direct reprogramming [32]. OPs thus generated were capable of maturation into OLs that form compact myelin both in vitro and in vivo. Transplantation of these OPs restored compact myelin in the corpus callosum of myelin-deficient shiverer mice and significantly extended their lifespan. These findings hold promise for establishing cell therapies in the CNS tackling both congenital and acquired myelin disorders.

Supplementary Materials: The following are available online at https:/ /www.mdpi.com/article/10 .3390 / cells10082166/s1, Figure S1: Isotype controls for immunocytochemistry experiments, Figure S2: Flow cytometry characterization of recovered aMSCs from cryopreservation, Figure S3: Semiquantitative RT-PCR analysis of aMSC-derived neurospheres, Figure S4: Semi-quantitative RT-PCR analysis of OPs, Figure S5: Maturation of OP-like cells into OLs after mitogen withdrawal, Figure S6: OPs recovered from cryopreservation generated myelin-forming OLs, Figure S7: Undifferentiated aM- 
SCs did not generate OLs in co-culture with dorsal root ganglion neurons, Figure S8: Ultrastructure of myelin in the corpus callosum of shiverer mice 12 weeks after injection of medium, Table S1: Primary antibodies for immunofluorescence, Table S2: Primary antibodies for flow cytometry, Table S3: Primers for RT-PCR, Table S4: Rat aMSC proliferation assay, Table S5: OP proliferation assay.

Author Contributions: Conceptualization, Y.-S.C., D.K.-Y.S.; methodology, Y.-P.T., G.L., M.T.-S.L.; data collection, Y.-P.T., G.L., K.L.-K.W., K.-W.T., M.T.-S.L.; data analysis, Y.-P.T., G.L., K.L.-K.W., K.-W.T.; writing—original draft preparation, Y.-P.T., G.L.; writing—review and editing, Y.-P.T., G.L., K.L.-K.W., Y.-S.C., D.K.-Y.S.; visualization, Y.-P.T., G.L., K.L.-K.W.; supervision, Y.-S.C., D.K.-Y.S., K.L.-K.W.; funding acquisition, Y.-S.C., D.K.-Y.S. All authors have read and agreed to the published version of the manuscript.

Funding: This work was supported by funding from the Health and Medical Research Fund (HMRF) of Hong Kong (Project No.: 05163156 \& 06173706) and CLKN BH Ltd.

Institutional Review Board Statement: Ethical review and approval of procedures on animals was obtained from the Committee on Use of Live Animals in Teaching and Research, The University of Hong Kong.

Informed Consent Statement: Not applicable.

Data Availability Statement: Datasets of the current study are available from the corresponding authors upon request.

Acknowledgments: We sincerely thank Alice Y.Y. Lui and X. Liang for assisting in the maintenance of cell cultures used in this study.

Conflicts of Interest: The authors declare no conflict of interest. The funders had no role in the design of the study; in the collection, analyses, or interpretation of data; in the writing of the manuscript, or in the decision to publish the result.

\section{References}

1. Franklin, R.J.M.; ffrench-Constant, C. Remyelination in the CNS: From biology to therapy. Nat. Rev. Neurosci. $2008,9,839-855$. [CrossRef]

2. Goldman, S.A. Stem and progenitor cell-based therapy of the central nervous system: Hopes, hype, and wishful thinking. Cell Stem Cell 2016, 18, 174-188. [CrossRef] [PubMed]

3. Stadelmann, C.; Timmler, S.; Barrantes-Freer, A.; Simons, M. Myelin in the central nervous system: Structure, function and pathology. Physiol. Rev. 2019, 99, 1381-1431. [CrossRef]

4. Cao, Q.; Xu, X.M.; DeVries, W.H.; Enzmann, G.U.; Ping, P.; Tsoulfas, P.; Wood, P.M.; Bunge, M.B.; Whittemore, S.R. Functional recovery in traumatic spinal cord injury after transplantation of multineurotrophin-expressing glial-restricted precursor cells. J. Neurosci. 2005, 25, 6947-6957. [CrossRef] [PubMed]

5. Windrem, M.S.; Schanz, S.J.; Guo, M.; Tian, G.F.; Washco, V.; Stanwood, N.; Rasband, M.; Roy, N.S.; Nedergaard, M.; Havton, L.A.; et al. Neonatal chimerization with human glial progenitor cells can both remyelinate and rescue the otherwise lethally hypomyelinated shiverer mouse. Cell Stem Cell 2008, 2, 553-565. [CrossRef] [PubMed]

6. Sharp, J.; Frame, J.; Siegenthaler, M.; Nistor, G.; Keirstead, H.S. Human embryonic stem cell-derived oligodendrocyte progenitor cell transplants improve recovery after cervical spinal cord injury. Stem Cells 2010, 28, 152-163. [CrossRef] [PubMed]

7. Sim, F.J.; McClain, C.R.; Schanz, S.J.; Protack, T.L.; Windrem, M.S.; Goldman, S.A. CD140a identify a population of highly myelinogenic, migration competent and efficiently engrafting human oligodendrocyte progenitor cells. Nat. Biotech. 2011, 29, 934-941. [CrossRef]

8. Kalladka, D.; Sinden, J.; Pollock, K.; Haig, C.; McLean, J.; Smith, W.; McConnachie, A.; Santosh, C.; Bath, P.M.; Dunn, L.; et al. Human neural stem cells in patients with chronic ischaemic stroke (PISCES): A phase 1, first-in-man study. Lancet 2016, 388, 787-796. [CrossRef]

9. Kim, H.J.; Seo, S.W.; Chang, J.W.; Lee, J.I.; Kim, C.H.; Chin, J.; Choi, S.J.; Kwon, H.; Yun, H.J.; Lee, J.M.; et al. Stereotactic brain injection of human umbilical cord blood mesenchymal stem cells in patients with Alzheimer's disease dementia: A phase 1 clinical trial. Alzheimers Dement. (N. Y.) 2015, 1, 95-102. [CrossRef]

10. Duma, C.; Kopyov, O.; Kopyov, A.; Berman, M.; Lander, E.; Elam, M.; Arata, M.; Weiland, D.; Cannell, R.; Crawat, C.; et al. Human intracerebroventricular (ICV) injection of autologous, non-engineered, adipose-derived stromal vascular fraction (ADSVF) for neurodegenerative disorders: Results of a 3-year phase 1 study of 113 injections in 31 patients. Mol. Biol. Rep. 2019, 46, 5257-5272. [CrossRef]

11. Hyun, I. The bioethics of stem cell research and therapy. J. Clin. Investig. 2010, 120, 71-75. [CrossRef] [PubMed]

12. Lo, B.; Parham, L. Ethical issues in stem cell research. Endocr. Rev. 2009, 30, 204-213. [CrossRef] [PubMed] 
13. Wang, S.; Bates, J.; Li, X.; Schanz, S.; Chandler-Militello, D.; Levine, C.; Maherali, N.; Studer, L.; Hochedlinger, K.; Windrem, M.; et al. Human iPSC-derived oligodendrocyte progenitors can myelinate and rescue a mouse model of congenital hypomyelination. Cell Stem Cell 2013, 12, 252-264. [CrossRef] [PubMed]

14. Windrem, M.S.; Osipovitch, M.; Liu, Z.; Bates, J.; Chandler-Militello, D.; Zou, L.; Munir, J.; Schanz, S.; McCoy, K.; Miller, R.H.; et al. Human iPSC glial mouse chimeras reveal glial contributions to schizophrenia. Cell Stem Cell 2017, 21, 195-208. [CrossRef] [PubMed]

15. Madhavan, M.; Nevin, Z.S.; Shick, H.E.; Garrison, E.; Clarkson-Paredes, C.; Karl, M.; Clayton, B.L.L.; Factor, D.C.; Allan, K.C.; Barbar, L.; et al. Induction of myelinating oligodendrocytes in human cortical spheroids. Nat. Methods. 2018, 15, 700-706. [CrossRef]

16. Tsui, Y.P.; Shea, G.K.H.; Chan, Y.S.; Shum, D.K.Y. Derivation of fate committed Schwann cells from adult rat bone marrow-derived neural progenitors. Methods Mol. Biol. 2018, 1739, 137-148.

17. Shea, G.K.H.; Tai, E.W.Y.; Leung, K.H.Y.; Mung, A.K.L.; Li, M.T.S.; Tsui, A.Y.P.; Tam, A.K.W.; Shum, D.K.Y.; Chan, Y.S. Juxtacrine signalling via Notch and ErbB receptors in the switch to fate commitment of bone marrow-derived Schwann cells. Eur. J. Neurosci. 2020, 52, 3306-3321. [CrossRef] [PubMed]

18. Mung, K.L.; Tsui, Y.P.; Tai, E.W.Y.; Chan, Y.S.; Shum, D.K.Y.; Shea, G.K.H. Rapid and efficient generation of neural progenitors from adult bone marrow stromal cells by hypoxic preconditioning. Stem Cell Res. Ther. 2016, 7, 146. [CrossRef]

19. Cai, S.; Tsui, Y.P.; Tam, K.W.; Shea, G.K.H.; Chang, R.S.K.; Ao, Q.; Shum, D.K.Y.; Chan, Y.S. Directed differentiation of human bone marrow stromal cells to fate-committed schwann cells. Stem Cell Rep. 2017, 9, 1097-1108. [CrossRef]

20. Cai, S.; Han, L.; Ao, Q.; Chan, Y.S.; Shum, D.K.Y. Human induced pluripotent stem cell-derived sensory neurons for fate commitment of bone marrow-derived Schwann cells: Implications for remyelination therapy. Stem Cells Trans. Med. 2016, 6, 1-13.

21. Ao, Q.; Fung, C.K.; Tsui, Y.P.; Cai, S.; Zuo, H.C.; Chan, Y.S.; Shum, D.K.Y. The regeneration of transected sciatic nerves of adult rats using chitosan nerve conduits seeded with bone marrow stromal cell-derived Schwann cells. Biomaterials 2011, 32, 787-796. [CrossRef] [PubMed]

22. García-León, J.A.; García-Díaz, B.; Eggermont, K.; Cáceres-Palomo, L.; Neyrinck, K.; Madeiro da Costa, R.; Dávila, J.C.; Baron-Van Evercooren, A.; Gutiérrez, A.; Verfaillie, C.M. Generation of oligodendrocytes and establishment of an all-human myelinating platform from human pluripotent stem cells. Nat. Protoc. 2020, 15, 3716-3744. [CrossRef] [PubMed]

23. Nolbrant, S.; Heuer, A.; Parmar, M.; Kirkeby, A. Generation of high-purity human ventral midbrain dopaminergic progenitors for in vitro maturation and intracerebral transplantation. Nat. Protoc. 2017, 12, 1962-1979. [CrossRef] [PubMed]

24. Lendahl, U.; Zimmerman, L.B.; McKay, R.D.G. CNS stem cells express a new class of intermediate filament protein. Cell 1990, 60, 585-595. [CrossRef]

25. Lu, Q.R.; Sun, T.; Zhu, Z.; Ma, N.; Garcia, M.; Stiles, C.D.; Rowitch, D.H. Common developmental requirement of Olig function indicates a motor neuron/oligodendrocyte connection. Cell 2002, 109, 75-86. [CrossRef]

26. Zhou, Q.; Anderson, D.J. The bHLH transcription factors Olig2 and Olig1 couple neuronal and glial subtype specification. Cell 2002, 109, 61-73. [CrossRef]

27. Chen, Y.; Balasubramaniyan, V.; Peng, J.; Hurlock, E.C.; Tallquist, M.; Li, J.; Lu, Q.R. Isolation and culture of rat and mouse oligodendrocyte precursor cells. Nat. Protocol. 2007, 2, 1044-1051. [CrossRef]

28. Rao, R.C.; Boyd, J.; Padmanabhan, R.; Chenoweth, J.G.; McKay, R.D. Efficient serum-free derivation of oligodendrocyte precursors from neural stem cell-enriched cultures. Stem Cells 2009, 27, 116-125. [CrossRef]

29. Hu, J.G.; Fu, S.L.; Wang, Y.X.; Li, Y.; Jiang, X.Y.; Wang, X.F.; Wang, X.F.; Qiu, M.S.; Lu, P.H.; Xu, X.M. Platelet-derived growth factor-AA mediates oligodendrocyte lineage differentiation through activation of extracellular signal-regulated kinase signaling pathway. Neuroscience 2008, 151, 138-147. [CrossRef] [PubMed]

30. McKinnon, R.D.; Smith, C.; Behar, T.; Smith, T.; Dubois-Dalcq, M. Distinct effects of bFGF and PDGF on oligodendrocyte progenitor cells. Glia 1993, 7, 45-254. [CrossRef] [PubMed]

31. Chan, J.R.; Watkins, T.; Cosgaya, J.M.; Zhang, C.; Chen, L.; Reichardt, L.F.; Shooter, E.M.; Barres, B.A. NGF controls axonal receptivity to myelination by Schwann cells or oligodendrocytes. Neuron 2004, 43, 183-191. [CrossRef]

32. Yang, N.; Zuchero, J.B.; Ahlenius, H.; Marro, S.; Ng, Y.H.; Vierbuchen, T.; Hawkins, J.S.; Geissler, R.; Barres, B.A.; Wernig, M. Generation of oligodendroglial cells by direct lineage conversion. Nat. Biotechnol. 2013, 31, 434-439. [CrossRef] [PubMed]

33. Milling, S.; Frede, A. Teaching tolerance: Diverse cellular interactions enable healthy maturation. Immunology 2021, 163, 237-238.

34. Graca, L. The contribution of B cells to transplantation tolerance. J. Clin. Investig. 2020, 130, 3406-3408. [CrossRef]

35. Meyer, N.; Richter, N.; Fan, Z.; Siemonsmeier, G.; Pivneva, T.; Jordan, P.; Steinhäuser, C.; Semtner, M.; Nolte, C.; Kettenmann, H. Oligodendrocytes in the mouse corpus callosum maintain axonal function by delivery of glucose. Cell Rep. 2018, 22, 2383-2394. [CrossRef] [PubMed]

36. Mount, C.W.; Yalçın, B.; Cunliffe-Koehler, K.; Sundaresh, S.; Monje, M. Monosynaptic tracing maps brain-wide afferent oligodendrocyte precursor cell connectivity. Elife 2019, 8, e49291. [CrossRef]

37. De Faria, O., Jr.; Pama, E.A.C.; Evans, K.; Luzhynskaya, A.; Káradóttir, R.T. Neuroglial interactions underpinning myelin plasticity. Dev. Neurobiol. 2018, 78, 93-107. [CrossRef] [PubMed]

38. Káradóttir, R.T.; Kuo, C.T. Neuronal activity-dependent control of postnatal neurogenesis and gliogenesis. Annu. Rev. Neurosci. 2018, 41, 139-161. [CrossRef] 
39. Jia, W.; Kamen, Y.; Pivonkova, H.; Káradóttir, R.T. Neuronal activity-dependent myelin repair after stroke. Neurosci. Lett. 2019, 703, 139-144. [CrossRef] [PubMed]

40. Singer, W.; Dietz, A.B.; Zeller, A.D.; Gehrking, T.L.; Schmelzer, J.D.; Schmeichel, A.M.; Gehrking, J.A.; Suarez, M.D.; Sletten, D.M.; Minota Pacheco, K.V.; et al. Intrathecal administration of autologous mesenchymal stem cells in multiple system atrophy. Neurology 2019, 93, e77-e87. [CrossRef] [PubMed]

41. Bain, B.J. Bone marrow biopsy morbidity and mortality. Br. J. Haematol. 2003, 121, 949-951. [CrossRef] [PubMed]

42. Malempati, S.; Joshi, S.; Lai, S.; Braner, D.A.V.; Tegtmeyer, K. Bone marrow aspiration and biopsy. N. Engl. J. Med. 2009, 361 , e28. [CrossRef] [PubMed] 